\title{
Vital Signs Result Standard Unit
}

National Cancer Institute

\section{Source}

National Cancer Institute. Vital Signs Result Standard Unit. NCI Thesaurus. Code C83465.

The standard unit of measure for vital signs results. 